\title{
A EDUCAÇÃO ESCOLAR INDÍGENA COMO FORTALECIMENTO DA IDENTIDADE CULTURAL DOS POTIGUARA DA PARAÍBA/BRASIL - CONSIDERAÇÕES INICIAIS
}

\author{
INDIGENOUS SCHOOL EDUCATION AS STRENGTHENING \\ THE CULTURAL IDENTITY OF THE POTIGUARA OF PARAÍBA / BRAZIL - \\ INITIAL CONSIDERATIONS
}

\begin{abstract}
Pedro Lôbo dos Santos*
Eduardo Dias da Silva**
\end{abstract}

Sou Tupã, sou Tupã, sou Potiguara. on Potiguara nesta terra de Tupã.

Tenbo arara, craúna e xexéu Todos os pássaros do céu,

Quem nos deu foi Tupã

Foi Tupã, foi Tupã, sou Potiguara.

(Toré indígena Potiguara)

\begin{abstract}
RESUMO
Este artigo, elaborado a partir de uma pesquisa qualitativa, consiste em apresentar algumas reflexões suscitadas a partir da relação entre escolarização e tradição como contribuintes para o fortalecimento da identidade étnico-cultural dos indígenas Potiguara em uma escola estadual de ensino fundamental e médio da Paraíba-Brasil, traduzidas na experiência do fazer pedagógico intercultural. Nesse contexto, infelizmente, há professores que se deparam com a falta de instrumentos pedagógicos e práticos para o desenvolvimento de estratégias no sentido de melhor exercerem a interculturalidade indígena. Sendo assim, por meio deste trabalho, é possível compreender o processo histórico para se garantir uma educação escolar indígena intercultural, específica e diferenciada para o povo indígena Potiguara da Paraíba, a qual é hoje assegurada por lei, orientada para atender as situações concretas da realidade indígena, tendo como finalidade a autonomia, a sustentabilidade, a política, a economia, a gestão territorial e cultural dos Potiguaras da Paraíba. Inclusive compreender a importância da educação escolar indígena para esse povo, em particular para sua juventude, como possibilidade de um futuro mais promissor. O desenvolvimento deste espaço no ambiente escolar não se limita às teorias e às metodologias de inclusão, mas se perpetua como caminho para novas reflexões sobre a escola intercultural indígena de e para estudantes (não) indígenas por práticas emancipatórias de indivíduos que se querem partícipes socialmente.
\end{abstract}

Palavras-chave: educação escolar indígena; Potiguara; interculturalidade; identidade cultural.

\section{ABSTRACT}

This article, elaborated from a qualitative research, consists of presenting some reflections raised from the relationship between schooling and tradition, as contributions to the strengthening of the ethnic-cultural identity of the potential indigenous in a local elementary and high schools in Paraíba/Brazil, translated into the experience of doing intercultural teaching. Unfortunately, there are teachers who are preparing for the lack of pedagogical and practical instruments in the development of strategies to improve the performance of indigenous interculturality. Therefore, through this work, it is possible to understand the historical process to guarantee an intercultural, specific and differentiated indigenous school education for the indigenous Potiguara people of Paraiba, which today is guaranteed by law, oriented to meet concrete situations of the indigenous reality, possessing the capacity for autonomy, political and economic sustainability, territorial management and culture of indigenous Potiguara of Paraíba, and understanding the importance of indigenous school education for these people, particularly for their youth, as the possibility of a more promising future, the development of this space in the environment school is not limited to theories and methodologies of inclusion, but is perpetuated as the path for new reflections on an indigenous intercultural school and for (non) indigenous students through emancipatory practices of individuals who identify themselves socially participants.

Keywords: indigenous school education; Potiguara interculturality; cultural identity.

\footnotetext{
* Mestrando em Educação pela Universidade Federal da Paraíba (UFPB), João Pessoa, PB, Brasil. lobobt@hotmail.com Orcid: https://orcid.org/0000-0002-7574-5467

** Doutor em Literatura Universidade de Brasília (UnB), Brasília, DF, Brasil. edu_france2004@yahoo.fr

Orcid: https://orcid.org/0000-0003-2555-6657
} 


\section{INTRODUÇÃO}

Para grande parte dos historiadores, a história educacional do Brasil se iniciou com a chegada dos primeiros padres da ordem dos Jesuítas em 1549, sob o comando do Padre Manuel da Nóbrega. Ao se afirmar isso, esquecese que os primeiros moradores que aqui viviam (os indígenas), já possuíam sua forma própria de educar e transmitir seus ensinamentos às suas crianças de modo espontâneo, como exemplificado por Silva (2010), Santos e Silva (2017), Silva e Borges (2019). Entretanto, sabe-se que tal educação se dava por toda a vida, isto é, mesmo depois de adultos, os indígenas continuavam a serem educados, pois eles viviam em comunidade, em uma economia natural e de subsistência. Obviamente que, havendo população nos territórios invadidos pelos colonizadores europeus, estes também viviam conforme uma determinada organização social, e uma forma educacional se fazia presente nessa configuração de povos originários (no caso desse artigo, população indígena Potiguara) e colonizadores europeus.

A primeira preocupação da Companhia de Jesus (ordem clerical dos padres jesuítas) era a expansão das atividades missionárias. Assim que se estabeleceram em território brasileiro, eles estabeleceram ambientes escolares e começaram os ensinamentos de leitura e de escrita por meio de cantigas e contos, segundo Almeida (2014) e Arnaut de Toledo e Ruckstadter (2003).

Dentro dos aldeamentos (organização habitacional dos povos indígenas), o grande objetivo em termos educacionais foi a catequização dos indígenas na fé cristã. Assim sendo, a chegada dos colonizadores europeus implicou na implantação de um ensino baseado na concepção da tábula rasa, no qual os indígenas precisavam ser "preenchidos" de conhecimentos europeus, menosprezando, ou mesmo, não levando em conta suas já consagradas maneiras de ensinar. Portanto, o processo de colonização evidenciou uma aculturação, uma vez que os colonizadores europeus tentaram impor sua cultura, seus costumes e tradições, segundo Bergamaschi e Silva (2007) e Silva (2010).

De acordo com Meliá (1979) e Silva (2010), ao implementar outros ambientes escolares nas comunidades indígenas, os jesuítas tinham o intuito de se aproximar dos povos para que pudessem conquistar a sua confiança, aprender suas línguas para, com isso, exercer poder sobre eles, para, assim, os manipular com maior facilidade e daí, doutriná-los conforme os objetivos da missão jesuíta. Esse processo era feito de tal forma que os indígenas eram intimidados a não ter o direito de optar por aceitar ou não a nova cultura imposta, no caso de rejeição seriam punidos e reprimidos por causa da sua rebeldia.

Ainda em consonância com supracitada autora, os indígenas não tinham noção do que seria um ambiente escolar nos moldes europeus, à época, e muito menos para que servia tal estrutura organizacional. Todavia esse novo ambiente escolar tinha a função de transformar a comunidade indígena e levá-la a seguir regras e padrões impostos pelos colonizadores europeus e seus agentes educadores (padres jesuítas), mudando todo o viés cultural indígena, principalmente a sua língua a qual eles tiveram que se abdicar e adequar-se ao português que era a língua utilizada por todos da Companhia de Jesus.

Segundo Bergamaschi e Gomes (2012) e Bergamaschi e Medeiros (2010), os povos indígenas, coerentes com suas vivências, apresentavam desde os primeiros contatos com os colonizadores europeus, um modelo próprio de educação que se mostrou de acordo com a visão eurocêntrica, como não sendo boas práticas de escolarização, visto que nas sociedades tradicionais, dentre as quais situam-se as comunidades indígenas, "as teorias do mundo, do homem e da sociedade são globais e unificadoras" (BERGAMASCHI, GOMES, 2012, p. 58). Ainda de acordo com essas autoras, nessas sociedades, o saber é acessível a todos, "dividido a partir de graus de iniciação que o eleva, e não a partir de uma setorização de conhecimentos que o fragmenta" (BERGAMASCHI; MEDEIROS, 2010, p. 62), como ocorre na organização e na transmissão dos conhecimentos escolares do modelo ocidental.

\section{0 QUE DIZEM AS LEIS NO BRASIL}

A luta e as reinvindicações por uma educação específica para os povos indígenas, levando em consideração suas línguas, rituais, tradições e organizações sociais e territoriais não foram inauguradas na atualidade. Constitui-se em um processo de conquistas empreendidas pelos povos indígenas de toda América Latina, que, historicamente, vêm exigindo uma educação escolar para as populações indígenas, tendo como princípio o ser diferenciado, o respeito pela alteridade, a valorização do intercultural e do bilinguismo. No que tange a legislação brasileira, esse processo educacional recebeu a denominação de Educação Indígena, Educação Escolar Indígena ou Educação Diferenciada, dependendo do período histórico-político vivido. 
Na Carta Magna de 1988 foi concedida aos povos indígenas do Brasil a possibilidade de novas relações com a perspectiva integracionista, reconhecendo com isso a pluralidade cultural brasileira existente e latente até então. Dessa forma, exaltando-se o respeito às diferenças e garantindo as especificidades étnicos-culturais desses povos, foram dados os primeiros passos para uma educação intercultural e diversificada.

Reverberando a Constituição Federal (Brasil, 1988), como já citado anteriormente, sendo a primeira base de fundamentação jurídico-legal do novo momento da educação escolar indígena no Brasil, concebe-se/ concretiza-se também o reconhecimento dos direitos das comunidades indígenas a uma educação escolar diferenciada, que respeite os processos educacionais próprios, de cada povo, conforme elucida o artigo 210 da Constituição Federal (Brasil, 1988), direito este confirmado em outras leis voltadas para o campo educacional. A título de exemplo, portanto, citamos a Lei de Diretrizes e Bases da Educação Nacional (LDBEN), de 1996, em seus artigos 78 e 79 (Brasil, 1996) e do Plano Nacional de Educação, de 2001, no qual traz consigo a temática da educação escolar indígena figurada no capítulo 09, com 21 metas (Brasil, 2001).

Ainda sobre essa temática, podemos citar os pareceres e resoluções do Conselbo Nacional de Educação (CNE), em conjunto com a Câmara de Educação Básica (CEB) que regulamentam, detalham e conceituam a educação escolar indígena nacional, merecendo destaque a resolução CNE/CEB n. 03, de 10 de novembro de 1999, que fixa, entre outras coisas, as diretrizes nacionais para o funcionamento das escolas indígenas e dá outras providências (Brasil, 1999). Outo ponto que merece destaque, e como uma das consequências dos avanços legais, é o fato de a educação escolar indígena, até meados de 1991, ter sido tutelada pela Fundação Nacional do Índio (FUNAI), passando, após essa data, para o âmbito organizacional do Ministério da Educação (MEC).

Portanto, a educação e os direitos indígenas garantidos pela Constituição Brasileira (1988) e pela LDBEN (1996) também são assegurados pelos seguintes documentos: Decreto n. 26, de 4 de fevereiro de 1991, que dispõe sobre a educação indígena no Brasil; a Lei n. 11.645, de 10 de março de 2008, que altera as regulamentações da Lei $\mathrm{n}^{\circ}$ 9.394, de 20 de dezembro de 1996. Este modifica com a Lei $\mathrm{n}^{\circ}$ 10.639, de 9 de janeiro de 2003 que estabelece as Diretrizes e Bases da Educação Nacional, para incluir no currículo oficial da rede de ensino a obrigatoriedade da temática História e Cultura Afro-brasileira e Indígena e o Decreto n. 6.861, de 27 de maio de 2009, que trata da Educação Escolar Indígena, define sua organização em territórios etnoeducacionais, e dá outras providências.

Direcionando o olhar para a legislação paraibana, temos a resolução CEE/PB n ${ }^{\circ}$ 207/2003, que estabelece normas para a organização, estrutura e o funcionamento das escolas indígenas no Sistema de Ensino da Paraíba, entre outros encaminhamentos (Paraíba, 2003). Embora reconhecidos os esforços federal e estadual respaldados por leis, a movimentação das políticas públicas para colocar os ambientes escolares a serviço dos interesses e necessidades dos povos indígenas, acontecem, muitas vezes, por iniciativas pensadas e executadas pela própria comunidade indígena, por meio de suas diversas representações, principalmente, pelos próprios professores indígenas, a exemplo da comunidade Potiguara, no estado da Paraíba, resultando, portanto, em atividades concretas de transformação a favor da educação escolar indígena, ao ponto de traduzir e expandir uma educação escolar autêntica e diferenciada, respeitando as especificidades socioculturais de cada povo como bem exemplificado por Santos e Silva (2017) e Silva e Borges (2019).

Desse modo, tais iniciativas trazem consigo, cada vez mais, uma esperança promissora e real às mudanças na educação escolar indígena no Brasil. Assim, a Constituição Federal de 1988, em conjunto com documentos, leis, resoluções subsequentes configuram-se como a expressão dos anseios de liberdade cultural, educacional, econômica, social, linguística e territorial dos povos indígenas, além de representar a luta pela democracia de todo povo brasileiro, sendo um instrumento legítimo de consagração, com força jurídica, das aspirações por justiça social e proteção da dignidade humana para todos e todas.

A partir das lutas pelo reconhecimento e legalização das terras dos povos originários (no caso dessa pesquisa, dos povos indígenas, mais especificamente o povo Potiguara), além do respeito e valorização da cultura, língua e identidade indígenas, percebe-se, uma certa resistência, no contexto político atual, no qual, inegavelmente, o ambiente escolar indígena aparenta assumir um novo papel frente aos grupos indígenas na atualidade, tais como: i) não se configurar mais como instrumento de dominação, e sim instrumento de reafirmação étnica e cultural, ii) fonte de conhecimento da lógica das sociedades envolventes, lançando às bases um diálogo sobre qual identidade indígena se constrói o sujeito pensante capaz de reivindicar o que a Constituição Federal (1988) e a Lei de Diretrizes e Bases da Educação Nacional (1996) garantem, e iii) escola bilíngue e diferenciada. 
Consoante o já supracitado neste artigo, a educação escolar indígena foi homologada conforme regem os artigos 231 e 232 da Constituição Federal (1988), trazendo no seu bojo a atuação e implementação da educação básica. Isso se traduz em um plano legal para o atendimento das necessidades educacionais dos povos indígenas e de seus interesses, respeitando, com isso, seus modos de vivências em comunidades, assim como suas organizações discutidas no âmbito das leis.

Voltando um pouco no tempo, a denominação educação escolar indígena foi, primeiramente, proposta por Meliá (1979) e ampliada, a posteriori, por Lopes (1985), segundo Collet (2006) e Silva e Borges (2019). Esses autores objetivaram diferenciar educação escolar indígena de educação indígena para que houvesse um melhor entendimento das posturas implícitas nessas duas perspectivas. Uma vez que, de acordo com eles, a educação indígena é a aprendizagem espontânea em que a criança ou jovem observam as outras pessoas e praticam as atividades corriqueiras nas aldeias, e assim aprendem sem maiores explicações suas tradições e costumes sociais. Sendo assim, o que lhes é transmitida configura-se como educação indígena, no qual todos são alunos e ao mesmo tempo professores, porque todos aprendem juntos. É por meio dessas ações que crianças e jovens são preparados para se tornarem sujeitos plenos e produtivos de seu grupo étnico, ao posso que a educação escolar indígena é a educação transmitida formalmente através do ambiente escolar.

\section{O POVO INDÍGENA POTIGUARA DA PARAÍBA}

O Brasil é uma nação constituída por grande variedade de grupos étnicos, com histórias, saberes, culturas e, na maioria das situações, com línguas próprias. Não é, portanto, diferente com a etnia Potiguara. O termo Potiguaras significa comedores de camarão, aqueles que habitam as terras de Akajutibiró (caju azedo ou bravo). Esse termo tem também suas raízes históricas na família linguística do Tupi. Segundo Marques (2009), o povo indígena Potiguara é um dos mais antigos povos pré-cabralianos a serem registrados nas crônicas oficiais das grandes navegações. No ano de 1501, a La Lettera, de Américo Vespúcio, batiza a Baía de Akajutibiró com o topônimo de Baía da Traição, segundo Moonen e Maia (2008[1992]) e Silva (2010).

Ainda de acordo com estes autores, Os Potiguaras só cederam aos colonizadores europeus depois de resistirem bravamente à dominação. Foram décadas de confronto que renderam episódios como: o ataque ao Engenho de Tracunhaém, as invasões francesas e holandesas no nordeste brasileiro, as Guerras Justas e entre outras. Os indígenas Potiguara integram os povos da família linguística Tupi, mas usam também com fluência a língua portuguesa, contudo já ocorrem iniciativas, no interior das comunidades da etnia e nas redes escolares indígenas, o incentivo e a reaprendizagem da língua materna, o Tupi, de acordo com relatos de Palitot (2005), Barcellos (2012) e Palhano Silva (2018). Há também os registros do povo guerreiro, comedores de camarão da terra de Acajutibiró, datando início da colonização no Brasil, como já mencionado anteriormente, pois "nesse contexto, a trajetória dos indígenas Potiguara é marcada por lutas contra os índios Tabajara e estrangeiros em defesa do território e pela resistência e (re) afirmação étnica" (PALHANO SILVA, 2018, p. 125).

Na Paraíba, de acordo com o Instituto Brasileiro de Geografia e Estatística (IBGE), no ano de 2010, a população Potiguara era de aproximadamente de 25 mil indivíduos, localizados no litoral norte, no Vale do Mamanguape. Segundo a Fundação Nacional do Índio (FUNAI), o território Potiguara ocupa atualmente um espaço de 33.757 hectares (ha), distribuídos em três áreas contíguas nos municípios paraibanos de Rio Tinto, Marcação e Baía da Traição, em 32 aldeias. A primeira, a Terra Indígena (TI) Potiguara, demarcada em 1983 e homologada em 1991, está situada nos três municípios e possui 21.238 ha. A segunda é a TI Jacaré de São Domingos, homologada em 1993, tem 5.032 ha e está localizada no município de Marcação. A terceira TI Potiguara de Monte-Mór está localizada nos municípios de Marcação e Rio Tinto e tem uma área de 7.487 ha (BRASIL, s/d).

Em relação à organização política, cada aldeia possui uma liderança indígena (cacique), escolhida pela comunidade. Essa escolha é realizada por meio de eleição ou, também, de indicação, ficando a liderança à frente da aldeia enquanto estiver correspondendo aos anseios da comunidade. Logo, o cacique tem a função de contribuir na organização da aldeia, intermediando conflitos internos, entre os parentes, como também entre os não indígenas, que, porventura coabitam na comunidade, além de organizar e mobilizar os movimentos de luta pela terra, ou em busca dos direitos básicos, como saúde e educação e, por vezes, defender o povo e o território contra possíveis invasores. Essas funções competem não só ao cacique, mas também a todos os indígenas da comunidade. Além dos 
caciques das aldeias, existe também a figura do cacique-geral, o qual representa a etnia Potiguara à frente dos órgãos públicos, de modo mais amplo, em âmbito estadual e nacional. O povo indígena Potiguara é sujeito de sua própria história, pois permanece no mesmo território desde a chegada dos colonizadores europeus em meados do século XVI (MOONEN, 2008; BARCELLOS, 2012; PALITOT, 2005).

Retomando pouco as tradições e rituais da etnia Potiguara, destacamos o Toré que representa um ritual em homenagem a suas ancestralidades, sendo elo de reafirmação da cultura e de suas tradições. Na maioria das vezes, esse ritual é praticado nos festejos religiosas ou sociais (na alegria, na tristeza e na luta), pois percebe-se o enfoque político, social e religioso, desse ritual. Conforme Oliveira (199) e Palilot (2005), o Toré é uma expressão lúdica e organizadora, íntima e emblemática, definida pelos indígenas como tradição, união e brincadeira, que é atualmente uma prática conhecida e presente na maioria das coletividades que se reivindicam como indígenas no estado da Paraíba.

Cada comunidade da etnia Potiguara realiza o seu Toré com singularidade, porque revela traços da etnicidade de cada grupo e de sua região, atribuindo com isso aspectos de identidade e das tradições próprias de cada comunidade, conforme características da região e heranças históricas dos ancestrais. No seio dessas comunidades indígenas, o Toré torna-se patrimônio cultural, bandeira de luta do movimento de emergência étnica. Quando se está envolvido na realização do citado ritual é preciso demonstrar firmeza e resistência frente ás lutas pelos direitos indígenas, reforçando os seus significados e atribuindo novos sentidos às práticas antigas. Por sua vez, o Toré se configura também em uma forma de afirmação mediante as lutas pela terra, que é considerada como a mãe desses povos.

Outro ponto cultural e identitário forte na etnia Potiguara é a pintura corporal usada no ritual do Toré, assim como os adornos. O vermelho e o preto são predominantemente as cores utilizadas pelos potiguaras. A cor vermelha é extraída do urucum, e a preta, do fruto (verde) do jenipapo. Existem diversas maneiras de se preparar tanto a cor vermelha como a preta, conforme relata Barcellos (2012).

A maioria dos indígenas da etnia Potiguara está ligada ao catolicismo. Visto que praticamente todas as aldeias possuem igrejas ou templos religiosos com devoção a algum santo escolhido pela comunidade, sob a coordenação da Paróquia São Miguel Arcanjo, da Baía da Traição, na Paraíba, segundo Marques (2009). Algumas edificações mais antigas, por exemplo, a de São Miguel (atualmente em ruínas, localizada na Aldeia São Miguel, no município de Baía da Traição) e a de Nossa Senhora dos Prazeres (localizada na Aldeia de Monte-Mór, no município de Rio Tinto) são símbolos históricos, étnicos e territoriais que remetem ao período colonial.

\section{ESCOLA ESTADUAL INDÍGENA DE ENSINO FUNDAMENTAL E MÉDIO PEDRO POTI}

As escolas indígenas localizadas nas aldeias da etnia Potiguara são, na maioria, destinadas ao ensino do primeiro ao quinto anos do ensino fundamental e uma ou outra fica reservada para o ensino médio (PARAíBA, 2003). O movimento indígena teve um papel fundamental na implementação da educação escolar indígena, pois ele é o responsável pelos primeiros passos na organização das escolas gestadas a partir dos anseios e que obedeceriam às especificidades e às necessidades dos indígenas (COLLET, 2006). Em 2003, depois de muita insistência e persistência junto aos órgãos competentes para fazer valer o cumprimento da Resolução 003/99 do Conselho Nacional de Educação, foram inauguradas duas Escolas Estaduais Indígenas diferenciadas e específicas: uma, na Aldeia Tramataia localizada no município de Marcação-PB, e a outra na Aldeia São Francisco localizada no município da Baía da Traição$\mathrm{PB}$ a qual inicialmente funcionou atendimento para o ensino fundamental e que a partir de 2005 foi implantado o ensino médio e a EJA (educação para jovens e adultos), de acordo com Paraíba (2003) e Silva (2017). Antes da sua construção e implementação, os alunos indígenas após concluírem a primeira fase do ensino fundamental em suas respectivas aldeias, eram obrigados a se deslocarem à sede do munícipio para darem continuidade aos estudos. Portanto, conforme Silva (2017), quanto à implantação das escolas indígenas,

o que define e delimita essa nova fase é a questão da criação e autogestão dos processos de educação escolar indígena. Essa é sua especificidade: os próprios povos indígenas discutirem, proporem e procurarem, não sem dificuldades, realizar seus modelos e ideais de escola, segundo seus interesses e necessidades imediatas e futuras. Seria, de fato, a tentativa concreta de transformar a "educação escolar para o índio" em "educação escolar do índio (SILVA, 2017, p. 67).

A escola estadual indígena de ensino fundamental e médio Pedro Poti está localizada na Aldeia São Francisco, no município paraibano de Baía da Traição. A escola foi inaugurada em 07 de julho de 2003, e tem o seu reconhecimento 
pela Constituição Federal de 1.988, por meio do decreto estadual n 5.051/2004 e pela resolução CNE/CEB 003/99. Portanto, há uma urgência na necessidade do reconhecimento, valorização cultural, a fim de oferecer uma educação específica, diferenciada, intercultural e contextualizada na revitalização da memória do povo Potiguara, uma vez que, ao se aplicar os saberes das diferentes áreas científicas e culturais das sociedades, sendo elas indígenas ou não, se almeja com isso uma preservação e evolução dos (não) indígenas Potiguara, na escola estadual indígena de ensino fundamental e médio Pedro Poti.

Outro ponto relevante na educação escolar indígena, na escola estadual indígena de ensino fundamental e médio Pedro Poti, é que, além dos discentes residentes na localidade, a escola acolhe outros discentes indígenas advindos das aldeias circunvizinhas, tais como: Aldeia Forte, Laranjeiras, Lagoa do Mato, Cumaru, São Miguel, Alto do Tambá, Mata Escura, Tracoeira, Santa Rita, Benfica, inclusive da própria sede do município.

O corpo docente é composto por indígenas, dos quais uma parte deles possui formação profissional em Licenciatura Intercultural, e os demais são graduados em áreas específicas do conhecimento. Pensando no fortalecimento e valorização da Cultura Indígena Potiguara, a escola estadual indígena de ensino fundamental e médio Pedro Poti agrega em seu Projeto Político Pedagógico (PPP) elementos que buscam promover o encontro entre os saberes da tradição partilhados pelas experiências dos anciãos repassadas pelos seus ancestrais, as quais acontecem na tradição oral e os conhecimentos históricos disciplinarmente formalizados pelos professores.

Recorrendo à pedagogia de projetos, a supracitada escola trabalha os conteúdos curriculares contextualizados e voltados para a realidade indígena. Entre esses projetos, é digno de nota os Jogos Indígenas Escolares, a Semana de Conscientização Indígena, o Projeto de Intervenção Pedagógica, a Semana Cultural e a Semana Ambiental.

Destaca-se também a Semana Cultural, que é uma iniciativa que contempla as seguintes categorias: religião, rituais e festas tradicionais, músicas, cantos e danças, textos escritos, língua indígena, medicina tradicional, jogos e brincadeiras, artesanato, pintura corporal, grafismo, contos, espiritualidade indígena. Além disso tudo, inclui outras categorias de expressão simbólica, as quais são trabalhadas em forma de oficinas. Essas oficinas têm como objetivo buscar a interação entre escola/família/comunidade, para que dessa forma possam incentivar, conscientizar e fortalecer a identidade cultural Potiguara, bem como a preservação do meio ambiente, promovendo, assim, ações que os incentivem a se desenvolver como cidadãos críticos, conscientes e protagonistas da sua própria história.

Para a realização da Semana Cultural na escola em tela, conta-se com a parceria dos professores, anciãos, artesãos, caciques, agentes comunitários de saúde e voluntários não indígenas na maioria das vezes como palestrantes, a exemplo de psicólogos, antropólogos e sociólogos convidados. No início da atividade, há um trabalho de conscientização, pesquisas, divulgações e atividades diárias para incentivar o alunado e as pessoas da comunidade a participarem. Houve muitas resistências, mas aos poucos todos foram se envolvendo e compartilhando as vivencias e práticas culturais.

Conforme observado, é na parte diversificada que o currículo atende a parte considerada específica da cultura do povo indígena Potiguara com disciplinas específicas como: Tupi, Etnohistória, Arte e Cultura. Por meio do ensino dessas disciplinas, o progresso interage com o despertar, o interesse e a preservação de sua cultura. Tal afirmativa se reforça no momento em que se tem o ensino da língua Tupi inserida no currículo escolar tendo como objetivo equipará-la com a mesma importância do ensino dado à língua portuguesa, pois o Tupi é um direito previsto pela constituição brasileira (1988), que estabelece a língua materna como autoridade máxima, como uma disciplina principal. Portanto,

É preciso compreender que esse modelo educacional possui uma função social de suma importância para as comunidades indígenas e a sociedade como um todo, que é contribuir para uma vida ressignificada, concedendo aos indígenas uma maneira de ensinar, ler, escrever e principalmente, contar sua própria história à sociedade não indígena, defendendo suas causas, seus direitos e, promovendo

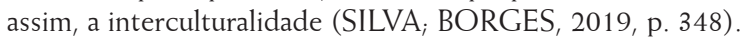

Outro momento importante que ocorre anualmente na referida escola é o ritual de formatura dos alunos concluintes do ensino médio. Esse momento representa para os formandos uma grande conquista por terem terminado essa etapa da educação básica em uma escola indígena, dentro da aldeia, reforçando, assim, a sua etnicidade. O espaço escolhido para a realização dos festejos da conclusão do ensino médio é a Barra do Camaratuba/Mataraca$\mathrm{PB}$, lugar natural, entre as águas doces e salgadas, em que rio, mar, fauna e flora se abraçam. O horário de início não é cronológico, depende da maré baixa. Para chegar ao local do evento, todos realizam a travessia pelo manguezal, 
pois o ambiente no qual é realizado o ritual fica em um grande banco de terra em pleno centro do leito do Rio Camaratuba, próximo a sua foz.

Os concluintes, trajados com suas vestes típicas, adornos e pinturas corporais indígenas, se posicionam em um grande círculo e sob as súplicas de bênçãos para a nova caminhada que seguirão. A equipe gestora da escola agradece ao deus Tupã, pela graça alcançada, mediante conclusão do ensino médio e convoca os discentes à reflexão, ao agradecimento, à preservação e à perpetuação dos aprendizados da tradição vivenciados na escola.

O pajé participa também fazendo reverência a Mãe Terra, solicitando força e iluminação da natureza, sobre as vidas dos alunos concluintes do ensino médio. Em seguida, no momento da certificação, os familiares participam da entrega dos canudos, os quais estão em um cesto, no meio da roda, que é abençoado pela defumação de ervas, proferida pelo pajé. A equipe gestora da escola preside a cerimônia anunciando cada etapa dos festejos. A comemoração com o ritual do Toré é o ápice da festa.

"O ritual da formatura é considerado prática educativa em que é possível envolver sujeitos que compreendem e incorporam os sentidos atribuídos às noções como organização e participação, além de assumirem a identidade étnica e manutenção de um imaginário (PALHANO SILVA, 2018, p. 46).

Como frutos da luta pela implantação da educação escolar indígena, no território Potiguara da Paraíba, muitos alunos, ao concluírem o ensino médio nas escolas indígenas, adentraram em vários cursos universitários nos campi I e IV da Universidade Federal da Paraíba (UFPB), localizados respectivamente nos municípios de João Pessoa, Mamanguape e Rio Tinto, a exemplos dos cursos superiores de Odontologia, de Serviço Social, de Pedagogia, de Antropologia, de Enfermagem, entre diversas Licenciaturas. Ao término desses cursos, os egressos às aldeias da comunidade Potiguara dão suas contribuições como profissionais que não abrem mão do pertencimento, das memórias e da relação cosmológica com a natureza, em uma relação que se constrói na respeitabilidade.

\section{CONSIDERAÇÕES FINAIS}

A questão central proposta pelo presente artigo foi contribuir na compreensão do processo histórico para se garantir uma educação escolar indígena intercultural, específica e diferenciada ao povo indígena Potiguara da Paraíba, a qual é hoje assegurada por lei, tendo a concepção de ensino baseada na metodologia da pesquisa, orientada para atender as situações concretas da realidade indígena, que, por sua vez, tem como finalidade a autonomia e a sustentabilidade política, econômica, de gestão territorial e cultural dos Potiguara da Paraíba.

As reflexões aqui apresentadas são uma tentativa de colocar em relevo o que se pensa ser uma ferramenta importante para pesquisas na obtenção de informação, resultado e austeridade na definição de sua aplicabilidade, a qual nesta pesquisa nomeia-se pesquisa colaborativa, de acordo com Apurinã (2017), por acreditar que este termo é o que mais se aproxima do que se compreende sobre o conceito de "alteridade". É importante salientar, que o termo ao longo dos anos recebeu de outros autores em seus mais variados textos e contextos, outras nomenclaturas: método investigativo, estudo etnográfico, pesquisa etnográfica, estudo de campo e assim por diante.

A comunidade indígena Potiguara tem clareza da importância da educação escolar indígena para o seu povo, em particular para a sua juventude, como possibilidade de um futuro mais promissor, pois, a comunidade indígena Potiguara "tem a função de fortalecer a luta dos povos indígenas por uma educação escolar indígena de qualidade, pautada nos princípios de uma democracia participativa e comunitária" (SILVA; BORGES, 2019, p. 347). Por tudo isso, a demanda por uma educação adequada e desenvolvida em harmonia com os seus projetos societários de futuro crescem em quantidade e complexidade, trazendo novos desafios aos sistemas de ensino. De imposta, a educação e a criação de escolas em terras indígenas passaram a ser demandas dessas populações, interessadas em adquirir conhecimentos sobre o mundo dentro e fora das aldeias.

\section{REFERÊNCIAS}

APURINÃ, Francisco. (2017) Um olhar reverso: da aldeia para universidade Amazôn. Rev. Antropol. v. 9, n. 1, p. $482-503$.

ALMEIDA, Maria Regina Celestino. (2014) Catequese, Aldeamentos e Missionação. In: FRAGOSO, João Luís Ribeiro; GOUVÊA, Maria de Fátima. (Org.). O Brasil Colonial 1443-1580. v. 1. Rio de Janeiro: Civilização Brasileira, p. 435-478. 
ARNAUT DE TOLEDO, Cézar de Alencar; RUCKSTADTER, Flávio Massani Martins. (2003) A Filosofia Educacional dos jesuítas nas cartas do Padre José de Anchieta. Acta Scientiarum (UEM), Maringá, v. 25, n.2, p. 257-265. Disponível em: <http://www.periodicos.uem.br/ojs/index.php/ActaSciHumanSocSci/article/view/2179/1359> Acesso em: 17 jun. 2020.

BARCELLOS, Lusival. (2012) Práticas educativo-religiosas dos índios Potiguara da Paraíba. João Pessoa: Editora da UFPB.

BERGAMASCHI, Maria Aparecida; GOMES, Luana Barth. (2012) A temática indígena na escola: ensaios de educação intercultural. Currículo sem Fronteiras, v.12, n.1, p. 53-69, jan/abr. 2012. Disponível em: < http://www.curriculosemfronteiras. org/vol12iss1articles/bergamaschi-gomes.pdf> Acesso em: 17 jun. 2020.

BERGAMASCHI, Maria Aparecida; SILVA, Rosa Helena Dias da. (2007) Educação escolar indígena no Brasil: da escola para índios às escolas indígenas. Agora, Santa Cruz do Sul, v. 13, n. 1, p. 124 - 150, jan/jun. 2007.

BERGAMASCHI, Maria Aparecida; MEDEIROS, Juliana Schneider. (20100 História, memória e tradição na educação escolar indígena: o caso de uma escola Kaingang. Revista Brasileira de História, São Paulo, v. 30, n. 60, p. 55-75.

BRASIL. (1988) Constituição da República Federativa do Brasil. Presidência da República. Casa Civil. Brasília.

BRASIL. (1996) Lei de Diretrizes e Bases da Educação Nacional (Lei n. 9.394, de 20 de dezembro de 1996). Presidência da República. Casa Civil. MEC: Brasília.

BRASIL. (1999) Resolução CEB n. 03, de 10 de novembro de 1999. Fixa Diretrizes Nacionais para o funcionamento das escolas indígenas e dá outras providências. MEC: Brasília.

BRASIL. (2001) Plano Nacional de Educação (Lei n. 10.172, de 09 de janeiro de 2001). Presidência da República. Casa Civil. MEC: Brasília.

BRASIL. (2010) Povos indígenas. IBGE. FUNAI. Ministério da Justiça. Brasília. Disponível em: <https://indigenas.ibge.gov.br/ images/indigenas/mapas/pop_indigena_per_2010.pdf> Acesso em: 21 jun. 2020.

BRASIL. Terras indígenas: o que é?. FUNAI. Ministério da Justiça. Brasília. S/d. Disponível em: < http://www.funai.gov.br/index. php/2014-02-07-13-24-32> Acesso em: 21 jun. 2020.

COLLET, Célia Letícia Gouvêa. (2006) Interculturalidade e Educação Escolar Indígena: um breve histórico. In: GRUPIONI, Luís Donisete Benzi (Org.). Formação de professores indígenas: repensando trajetórias. MEC/SECADI. Brasília.

LOPES, Eliane Marta T. (1985) Colonizador - colonizado: uma relação educativa no movimento da história. Belo Horizonte: UFMG.

MARQUES, Cássio Ferreira (Org.). (2009) Lendas e Causos do Povo Potiguara. João Pessoa: Editora da UFPB.

MELIÁ, Bartolomeu. (1979) Educação indígena e alfabetização. São Paulo: Loyolla.

MOONEN, Frans. (1988) Antropologia aplicada. São Paulo: Ática.

MOONEN, Frans; MAIA, Luciano Mariz. (Orgs.). (2008[1992]) Etnohistória dos índios Potiguara. João Pessoa: Procuradoria da República na Paraíba/Secretaria da Educação e Cultura do Estado da Paraíba. Disponível em: < http://www.dhnet.org.br/ direitos/militantes/lucianomaia/moonen_1500_1983_indios_potiguaras.pdf $>$ Acesso em: 21 jun. 2020.

OLIVEIRA, João Pacheco de (Org.) (1999). A Viagem da volta: Etnicidade, Política e Reelaboração Cultural no Nordeste Indígena (Territórios Sociais, 2) Rio de Janeiro, Contra Capa.

PAIVA, José Maria. Educação jesuítica no Brasil colonial. (2007) In: LOPES, Eliane Marta T; FARIA FILHO, Luciano M. de; VEIGA, Cynthia G. (Orgs.) 500 anos de educação no Brasil. 3. Ed. Belo Horizonte: Autêntica. 
PALHANO SILVA, Paulo Roberto. (2018) A economia indígena Potiguara: a arte no artesanato é patrimônio cultural Potiguara sustentando potencialidades culturais, sociais, econômicas, religiosas e simbólicas. In: PALHANO SILVA, Paulo Roberto. Práticas educativas e Economia Solidária no Vale do Mamanguape. João Pessoa: Ideia.

PALITOT, Estevão Martins. (2005) Os Potiguara da Baía da Traição e Monte-Mór: bistória, etnicidade e cultura. Dissertação (Mestrado em Sociologia) - Universidade Federal da Paraíba, João Pessoa.

PARAÍBA. (2003) Resolução n. 207/2003. Governo do Estado da Paraíba. Secretaria da Educação e Cultura. Conselho Estadual de Educação. João Pessoa.

SANTOS, Cassio Cabral (Org.) (2014). Legislação Educacional da Paraíba. João Pessoa: Editora UNEPI.

SANTOS, Pedro Lôbo dos; SILVA, Eduardo Dias da. (2017) Além do arco e flecha: a construção étnico-identitária a partir da educação bilíngue indígena Potiguara-PB. Revista Espaço Acadêmico, v. 17, n. 199, p. 49-58, 5 dez. 2017. Disponível em: <http://periodicos.uem.br/ojs/index.php/EspacoAcademico/article/view/37842/21308> Acesso em: 17 jun. 2020.

SILVA, Patrícya Karla Ferreira. (2010) Educação escolar indígena: uma análise a partir da perspectiva da sexualidade e gênero no município indígena de Baía da Traição/PB. Dissertação (Mestrado em Serviço Social) - Universidade Federal da Paraíba, João Pessoa, PB.

SILVA, Maria Alda Tranquilo da. (2017) Saberes docentes constituídos na Prática Pedagógica de Professores da EJA indígena Potiguara na Baía da Traição -PB. Dissertação (Mestrado em Educação) - Universidade Federal da Paraíba, João Pessoa.

SILVA, Simone Maria; BORGES, Claudia Cristina do Lago. (2019) Educação Escolar indígena Potiguara: uma análise material e estrutural. Tellus, ano 19, n. 38, jan./abr. DOI: https://doi.org/10.20435/tellus.v19i38.592

Recebido: 5/11/2020

Aceito: 4/3/2021

Publicado: 22/3/2021 